\section{AOA low-back pain research project}

The AOA Bureau of Research, with the support of the AOA Board of Trustees, has embarked upon a pilot study to assist in the development of a significant research project on manipulative medicine. The project will examine the effect of osteopathic manipulative treatment on low-back pain. Myron S. Magen, D.O., dean of the Michigan State University College of Osteopathic Medicine, has been appointed as the principal investigator, with W. Douglas Ward, Ph.D., director of the AOA Department of Education, serving as the project administrator. Financial support for the first phase of the project has come in the form of grant from the Quad City Osteopathic Foundation of Davenport, Iowa, in the amount of $\$ 90,000$.

Currently underway, the initial phase involves the design of a clinical research protocol. This critical segment of the research project is being directed by a design panel, which is chaired by Dr. Magen and includes the following members: Gunnar Anderson, M.D., professor and associate chairman of the Department of Orthopedic Surgery, Rush-Presbyterian-St. Luke's Medical Center, Chicago; Philip Greenman, D.O., associate dean and professor of biomechanics, MSUCOM, East Lansing; Victor Hawthorne, M.D., professor emeritus, Department of Epidemiology, University of Michigan, School of Public Health, Ann Arbor; and Fletcher McDowell, M.D., professor of neurology, Cornell University Medical School, Cornell, New York.

The colleges of osteopathic medicine will be invited to participate; on the basis of criteria being developed, they will be chosen on their ability and willingness to meet the protocol characteristics.

During the past 15 years, at least ten controlled clinical trials of spinal manipulation have been reported in the literature. In a survey by Winer, ${ }^{1}$ it was shown that most of these trials were conducted in Europe or Australia. None of the reported trials was conducted by osteopathic physicians in the United States.

The difficulties in clinical trials of spinal manipulation are many and significant. The AOA research project is important not only to the osteopathic medical profession, but to the entire health care profession and its patients as well. Definitive, well-designed, controlled studies such as the low-back pain research project are vital.

THOMAS W. ALLEN, D.O., FACOI

1. Winer, C.E.R.: A survey of controlled clinical trials of spinal manipulation. In Aspects of manipulative therapy, edited by E.F. Glasgow, et al. Ed. 2. Churchill Livingstone, Inc., New York, 1985

\section{Twice learned}

It has been said that to teach is to twice learn. Since the time of Hippocrates, physicians have been admonished to share their knowledge and experience with their colleagues, particularly those in training. In reality, all of us, regardless of age, are literally "in training," due to the rapid advancements that are taking place in medical care today.

As our profession grows, the demand for teachers at both the graduate and undergraduate levels also increases. It has been said that the higher one goes on the so-called educational ladder, the less likely one is to find teachers who have been taught anything about the art of teaching. Gradually, we are seeing colleges and medical schools sending faculty members for postdoctoral classes in the art and methodology of the teaching professions.

There are few natural teachers. For the most part, effective teachers have themselves become students of pedagogic techniques, and, in medicine, particularly of the art of bedside teaching and learning. It is not sufficient for medical instructors to lead students through a maze of "unusual cases," only to discover that very little time has been spent teaching the fundamentals of diagnosis and treatment of the common problems encountered in the daily practice of medicine.

The medical schools of today, whether allopathic or osteopathic, are responding to the public demand that a physician's life should be one of continuing medical education. Education does not stop at commencement day when the coveted D.O. or M.D. degree is awarded. Actually, graduation is an admission ticket to a lifetime of learning and, hope- 
fully, of sharing the results of that learning and experience with one's colleagues. There are very few, if any, of our 15 colleges of osteopathic medicine that could not use part-time or full-time faculty, particularly those with either natural or acquired teaching ability. Interestingly, some institutions offer regular series of lectures on teaching and learning techniques.

Teaching and learning must have high priority in our educational system. Teaching is truly twice learning.

GEORGE W. NORTHUP, D.O., FAAO

\section{Fibromyalgia syndrome: New or old?}

Fibromyalgia syndrome, with a U.S. incidence of 3 to 6 million cases, is a subject of both historic interest and current investigation. Several decades ago, the condition was labeled "muscular rheumatism." Because it did not meet any specific set of symptoms or objective findings, it next became known as "psychogenic rheumatism." This terminology did not hold, however, because testing failed to prove that the syndrome was primarily a psychogenic problem. Later on, it was identified by the loosely defined term, "fibrositis." All of these misnomers are strikingly similar to the present description of fibromyalgia syndrome.

Current literature notwithstanding, the condition continues to be controversial. As stated in a recent article ${ }^{1}$ and supporting editorial ${ }^{2}$ in The Journal of the American Medical Association, Don L. Goldenberg, M.D., of Boston University School of Medicine, believes conclusively that fibromyalgia is a specific syndrome with uniform signs and symptoms. His obligatory criteria for diagnosis include: chronic generalized aches, pains, or stiffness involving at least 3 anatomic sites for 3 months or more; the absence of other systemic conditions that could account for the patient's symptoms; and multiple tender points at the characteristic locations.

The author's list of minor criteria includes disturbed sleep, general fatigue, subjective swelling, numbness, neck or shoulder pain, chronic headaches, and irritable bowel symptoms. In the series of 118 patients in Dr. Goldberg's study, each met the three basic criteria (with each having at least six tender points) and each met at least four of the minor criteria.

The author makes a clear distinction between tender points and trigger points. He suggests that tender points occur at predictable anatomic sites; unlike trigger points, they have no specific pain references to strictly localized myofascial irritations.
I recall at least three osteopathic physicians who, following similiar tender tracking, reported on tender points located in predictable areas. S.C. Edmiston, D.O. (JAOA 22:137-9, November 1922 and 23:475-90, March 1924), Harold I. Magoun, D.O. (JAOA 36:453-6, June 1937), and Wesley P. Dunnington, D.O. (JAOA 64:366-71, December 1964) all described patterns of tender points that are not only similar to each other, but that are similar to the "recently discovered" fibromyalgia syndrome. The fact that the syndrome has currently attracted great interest provides an excellent opportunity for the osteopathic profession to carry out further investigation. Manipulative techniques relative to myofascial problems, the introduction of muscle energy techniques, and the trigger points mentioned by Lawrence H. Jones, D.O., in association with his strain/counterstrain theory, all begin to seemingly have a common denominator. Students of Chapman's reflexes will agree that these, too, have an interlocking interest.

The fibromyalgia syndrome appears to be a much more prevalent health care problem than has previously been recognized. It provides us with an excellent opportunity to review our own work and clinical observations.

GEORGE W. NORTHUP, D.O. FAAO

\footnotetext{
1. Goldenberg, D.L.: Fibromyalgia syndrome. An emerging but controversial condition. JAMA 257:2782-7,22/29 May 87

2. Bennett, R.M.: Fibromyalgia (editorial). JAMA 257:2802-3, 22/29 May 87
}

\section{$\overline{\text { editorial comment }}$}

Natural chemicals released into the bloodstream when a person is under stress may strengthen the body's ability to fight off disease and could prove to be an important factor in the control of disorders that attack the immune system, according to researchers at the University of Illinois at Chicago (UIC).

Enkephalins, which come primarily from the pituitary and adrenal glands, are a type of chemical known as neuropeptides.

Immunologist and principal investigator David Ou, M.D., and researcher Mark D. Wiederhold, said that the discovery that they increase the numbers of helper cells and natural killer cells within the immune system during stressful situations could lead to new insights into the relationship between stress and disease.

The assertion of Andrew Taylor Still that the continued on page $476 / 61$ 